Signal Integrity 

Samuel H. Russ

\section{Signal Integrity}

Applied Electromagnetics and Professional Practice

自 Springer 
Samuel H. Russ

University of South Alabama

Mobile, AL, USA

ISBN 978-3-319-29756-9

ISBN 978-3-319-29758-3 (eBook)

DOI 10.1007/978-3-319-29758-3

\section{Library of Congress Control Number: 2016931870}

(C) Springer International Publishing Switzerland 2016

This work is subject to copyright. All rights are reserved by the Publisher, whether the whole or part of the material is concerned, specifically the rights of translation, reprinting, reuse of illustrations, recitation, broadcasting, reproduction on microfilms or in any other physical way, and transmission or information storage and retrieval, electronic adaptation, computer software, or by similar or dissimilar methodology now known or hereafter developed.

The use of general descriptive names, registered names, trademarks, service marks, etc. in this publication does not imply, even in the absence of a specific statement, that such names are exempt from the relevant protective laws and regulations and therefore free for general use.

The publisher, the authors and the editors are safe to assume that the advice and information in this book are believed to be true and accurate at the date of publication. Neither the publisher nor the authors or the editors give a warranty, express or implied, with respect to the material contained herein or for any errors or omissions that may have been made.

Printed on acid-free paper

This Springer imprint is published by Springer Nature

The registered company is Springer International Publishing AG Switzerland 


\section{Contents}

1 The Basics: Charge, Energy, Time, and Distance . . . . . . . . . . 1

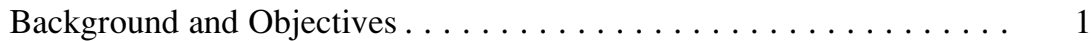

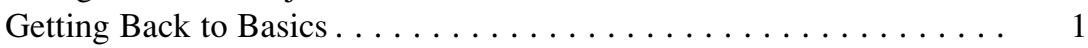

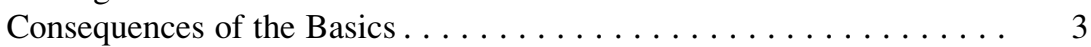

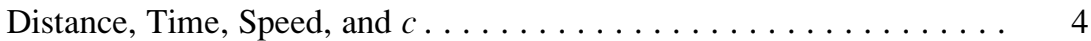

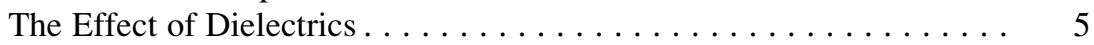

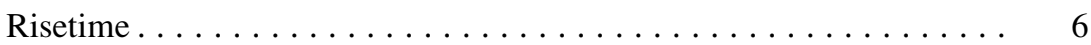

Lumped Versus Distributed . . . . . . . . . . . . . . . 7

Combining Risetimes . . . . . . . . . . . . . . . . . . 9

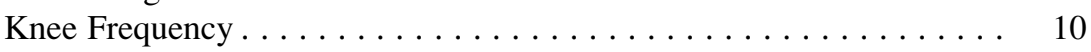

Homework . . . . . . . . . . . . . . . . . . . . . 11

2 Practical Matters: Circuit Boards and Debugging . . . . . . . . . . . 13

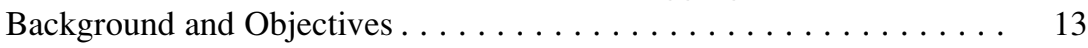

Components and Component Packages . . . . . . . . . . . . . . 13

Engineer's Notebook: More About Component Packaging . . . . . . . 14

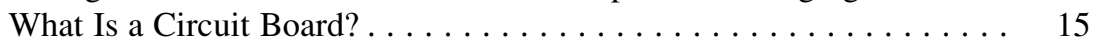

How Are Circuit Boards Made? . . . . . . . . . . . . . . . . . . 17

How Are Circuit Boards Used to Make a Product? . . . . . . . . . . . . . 19

Backup: How Did We Get Here? . . . . . . . . . . . . . . . . . 22

How Are Circuit Boards Designed $\ldots \ldots \ldots \ldots 22$

The Board Is Dead. Now What? . . . . . . . . . . . . . . 23

Homework .......................... 24

3 Gates, Packaging, and Boards: Properties and Modeling . . . . . . 25

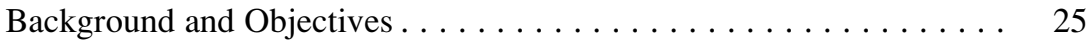

What Limits What Is Possible $\ldots \ldots \ldots \ldots \ldots$. . . . . . . . . . . . 25

Power and Heat Dissipation . . . . . . . . . . . . . . . . 27

Summarizing the Effects . . . . . . . . . . . . . . . . . . 29

Simplest Gate Model . . . . . . . . . . . . . . . . . . . . . . . . 29 
Electrical Modeling ....................... 31

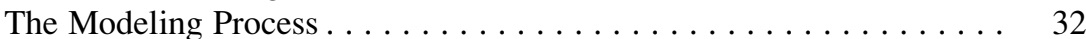

Engineer's Notebook: More About Capacitors . . . . . . . . . . . . . 34

The Limits of Modeling . . . . . . . . . . . . . . . . . . 35

Homework .......................... 36

4 Circuit Elements: Resistance, Capacitance, and Inductance . . . . . 37

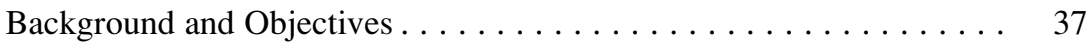

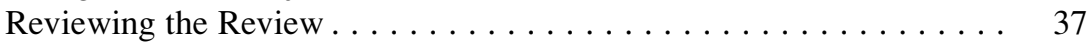

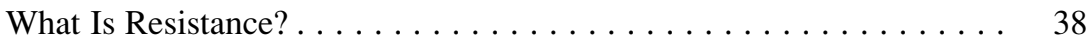

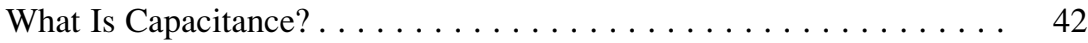

Finding Capacitance $\ldots \ldots \ldots \ldots \ldots \ldots \ldots \ldots \ldots \ldots \ldots \ldots \ldots \ldots \ldots$

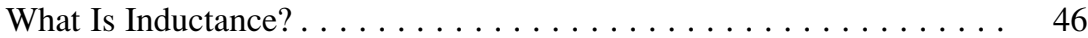

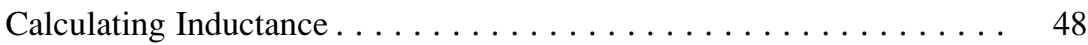

Inductance and Return Current . . . . . . . . . . . . . . . . 49

Inductance and the Skin Effect ................. 50

Homework .......................... 52

5 Ground Bounce and Ringing $\ldots \ldots \ldots \ldots \ldots \ldots \ldots \ldots \ldots \ldots$

Background and Objectives.................... 55

The Role of Inductance . . . . . . . . . . . . . . . . . 55

What Is Ground Bounce? . . . . . . . . . . . . . . 56

Results of Ground Bounce . . . . . . . . . . . . . . . . . . 59

Engineer's Notebook: The Ground Bounce Pulse . . . . . . . . . . . 59

Engineer's Notebook: The Self-Resetting Board . . . . . . . . . . . 60

Minimizing Ground Bounce $\ldots \ldots \ldots \ldots \ldots \ldots \ldots \ldots \ldots$

What Is Ringing? . . . . . . . . . . . . . . 62

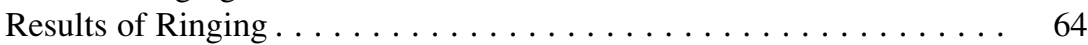

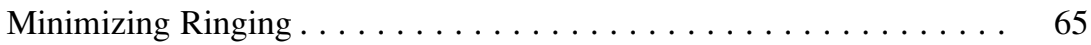

So Where Is Ringing Seen and Not Seen Today? . . . . . . . . . . 65

Homework . . . . . . . . . . . . . . . . . . . . . 66

\section{Distributed Analysis: Transmission Lines, $Z_{0}$, Reflections,}

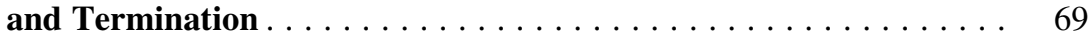

Background and Objectives...................... 69

Where Can You See a Transmission Line? . . . . . . . . . . . . . 69

Transmission Line: The View from the Inside . . . . . . . . . . . . 70

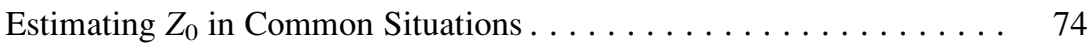

Approximate Model of a Transmission Line . . . . . . . . . . . 75

The Left Hand and the Right Hand: Reflection

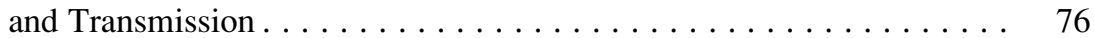

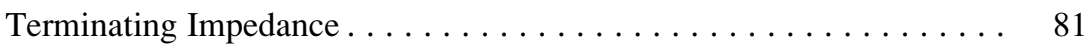

Departures from the Ideal . . . . . . . . . . . . . . . 83

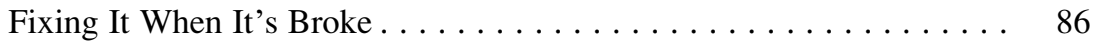

Engineer's Notebook: The High-Speed Bus Disaster. . . . . . . . . . 86

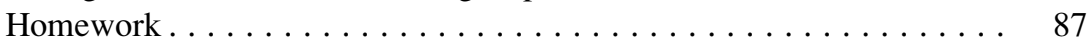


7 Lossy Transmission Lines . . . . . . . . . . . . . . . . . . . . . 91

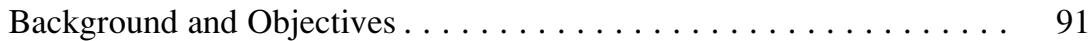

What Is Attenuation and How Is It Measured $\ldots \ldots \ldots . \ldots . \ldots 91$

Frequency-Dependent Attenuation . . . . . . . . . . . . . . 93

Dielectric Loss . . . . . . . . . . . . . . . . . . . . . . . . . . . . 93

How Does Dielectric Loss Affect $\varepsilon$. . . . . . . . . . . . . . . . . . . . . 94

How Does Dielectric Loss Affect Signal Propagation? . . . . . . . . . . . . . . . 96

Homework . . . . . . . . . . . . . . . . . . . . . . . . . 99

8 Differential Signaling . . . . . . . . . . . . . . . . . . . . 101

Background and Objectives . . . . . . . . . . . . . . . . 101

What Is Differential Signaling and How Does It Help? . . . . . . . . . . 101

What Is $Z_{\text {diff }}$. . . . . . . . . . . . . . . . . . . . . . . 103

Obstacles: Clock Jitter and Common-Mode Signals . . . . . . . . . . . . 105

Termination Strategies Revisited . . . . . . . . . . . . . . . . 107

Homework . . . . . . . . . . . . . . . . . . . . . . . . . . . . . 109

9 Crosstalk ........................... 111

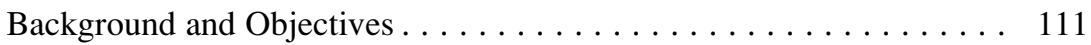

What Is Crosstalk . . . . . . . . . . . . . . . . . . . . . 111

Near-End Versus Far-End Crosstalk . . . . . . . . . . . . . . . . . . 113

Estimating and Reducing Crosstalk . . . . . . . . . . . . . . . . 117

Diagnosing Crosstalk . . . . . . . . . . . . . . . . . . . . . 117

Engineer's Notebook: Crosstalk Problems . . . . . . . . . . . . . . . 118

Homework . . . . . . . . . . . . . . . . . . . . . 119

10 Power Distribution Network: Frequency Domain Analysis . . . . . . . 121

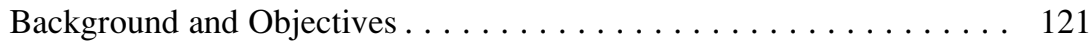

The Power Distribution Network . . . . . . . . . . . . . . . . . . 121

Power Supplies and Resonance . . . . . . . . . . . . . . . . . . . . . . . . . . . . . 123

Design Strategy: The Big Picture . . . . . . . . . . . . . . . . . . . . . . . . . . . . . . . 126

Design Strategy: The Details . . . . . . . . . . . . . . . . . . . . . 127

Design Strategy: The Role of Simulation . . . . . . . . . . . . . . . . . . . . . . . 130

Selecting Bypass Capacitors . . . . . . . . . . . . . . . . . 133

Homework . . . . . . . . . . . . . . . . . . . . . . . . . 134

11 EMI/EMC: Design and Susceptibility . . . . . . . . . . . . . . 137

Background and Objectives . . . . . . . . . . . . . . . . . . 137

EMI/EMC . . . . . . . . . . . . . . . . . . . . . . . . 137

Circuit-Board Design . . . . . . . . . . . . . . . . . . . . . . . 139

Engineering Notebook: Mounting Holes,

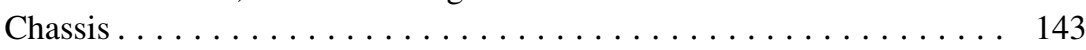

Cabling . . . . . . . . . . . . . . . . . . . . . . . . . . . . . 144

Legal Certification: Standards and Test Requirements . . . . . . . . . . . 145

Engineering Notebook: Get Down Here Right Away . . . . . . . . . . . 146

Homework . . . . . . . . . . . . . . . . . . . . 147 
12 Electrostatic Discharge . . . . . . . . . . . . . . . . . . . . . . . 149

Background and Objectives . . . . . . . . . . . . . . . . . . 149

What Is Electrostatic Discharge? . . . . . . . . . . . . . . . . . . . 149

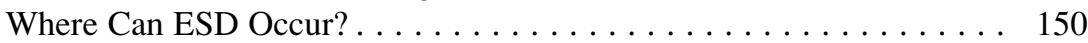

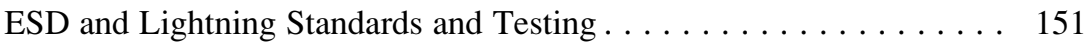

Components to Manage ESD . . . . . . . . . . . . . . . . . . 152

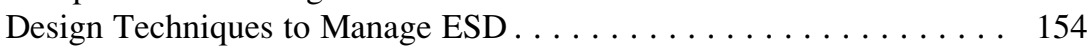

Homework . . . . . . . . . . . . . . . . . . . . . . . . 155

13 Clocks, Jitter, and Phased-Lock Loops . . . . . . . . . . . . . . 157

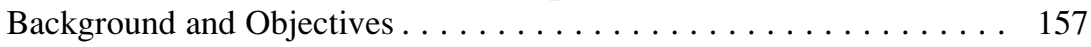

Clock Jitter and Clock Skew . . . . . . . . . . . . . . . . . . . . . 157

Clock Sources . . . . . . . . . . . . . . . . . . . . . . . . 158

Origins of Clock Jitter and Layout to Reduce It . . . . . . . . . . . 160

Engineer's Notebook: The Crystal Layout . . . . . . . . . . . . . . 161

Homework . . . . . . . . . . . . . . . . . . . . . . . . . 161

14 More Practical Matters: Testing, Debugging, DFX,

and Quality Management ....................... 163

Background and Objectives..................... 163

Testing a Board: The Oscilloscope . . . . . . . . . . . . 163

Debugging a Board: Overview . . . . . . . . . . . . . . . . 165

Transitioning to Mass Production ................. 166

Engineer's Notebook: Confusing Connectors . . . . . . . . . . . . 168

Engineer's Notebook: Factory Fire . . . . . . . . . . . . . . . . . . 170

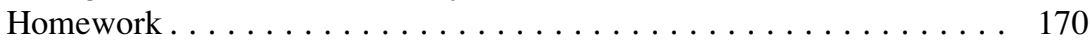

15 Practical Matters III: Commercial and Legal Implications,

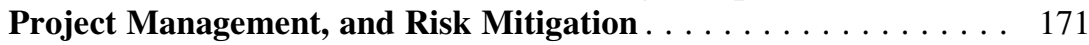

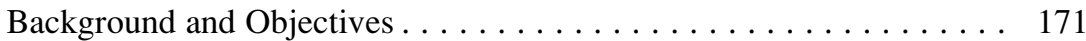

Legal Aspects of Design . . . . . . . . . . . . . . . . . . . 171

Commercial Aspects of Design . . . . . . . . . . . . . . . . . . 173

Engineering Notebook: Predicting What Comes Next . . . . . . . . 175

Project Management . . . . . . . . . . . . . . . . . . . . 176

Risk Mitigation . . . . . . . . . . . . . . . . . . . 177

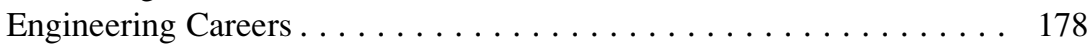

Homework. . . . . . . . . . . . . . . . . . . . . . . . . 179

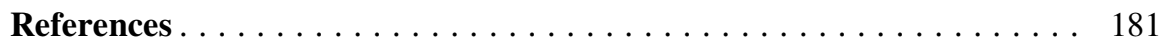




\section{Introduction}

\section{Why Study This Subject?}

It is my hope that this book will help the reader understand applied electromagnetics. The book will be getting into some fairly complicated and very abstract topics, but remember - the emphasis will be on the practical or "applied" aspects of the subject.

Have you ever wondered why the flight attendant tells you to turn off your cell phone at takeoff? Have you ever wondered how your hard drive talks to your computer at 3 gigabits per second over a very thin cable? How did the company that makes your computer's processor get it to work at $3 \mathrm{GHz}$ ?

All of these daily examples are part of the world of signal integrity. Signal integrity is the science (and art) of designing systems that carry signals intact over distance and that do not interfere with each other. The subject lies at the intersection of electromagnetics and computer engineering, and so understanding it is vital for computer engineers in the gigahertz era.

\section{Why This Book?}

One may wonder whether a textbook like this is worth the cost. In the case of this book, it turns out there are two good reasons. First, this subject is extremely important and rarely taught in college. So this book is not only what students will use to take this class, it can also become a permanent part of a technical bookshelf and might even bail you out if you get stuck on a signal integrity issue. This book is designed specifically for that purpose - the technical bailout. Second, the book has plenty of examples and some real-world testimonials based on my own experiences. 


\section{Why Are We Here, and Where Is "Here"?}

The twin revolutions of computing and communications have achieved the dream of a world with nearly instantaneous access to all corners of the globe and with a seemingly limitless body of knowledge at our fingertips. All of this was brought about through the hard work of roughly three generations of electrical and computer engineers who developed the computer chips, interconnections, and communications systems that made it all possible.

As the twin revolutions were unfolding in the 1995 time frame (right about the time the World Wide Web was launched), clock frequencies and data rates nudged up into hundreds of megahertz. (I still remember my whopping $90 \mathrm{MHz}$ Pentium computer.)

At this point, a very crucial change occurred.

It turns out that there are two ways of thinking about a wire. One can use a "lumped" approximation and assume the wire is a zero ohm resistor with the same voltage at every point, or one can use a "distributed" approximation and assume the wire has inductance and can have different voltages at different points.

When the $100 \mathrm{MHz}$ barrier was crossed, wires on computer motherboards stopped being wires (in the lumped sense) and started becoming transmission lines (i.e., distributed wires).

The only way to design systems today that work correctly is to use distributed analysis. This is the traditional domain of electromagnetics experts. Computer engineers literally need to know most of the methods that were used to design microwave systems back in the 1960s. This is where we are today - in a world that must be modeled using distributed analysis.

This book will teach how to convert fluently between frequency, time, and distance. This book will then teach how signals propagate, how they interfere, what can go wrong, and how to fix it. The focus in this book is on the design of realworld systems using physical principles and in cultivating an engineering intuition based on physics and measurements. Along the way, the book also looks at the design of digital systems from a manager's perspective so you can both be a better informed engineer and become a successful manager one day (if you want to).

What makes digital design challenging? I think the challenge lies in three very common ingredients. First, digital designs are almost always cost-constrained, especially consumer items like MP3 players. Second, the increasing clock speeds (more accurately, the faster rise and fall times) make the design more complicated because everything has to work up to higher frequencies. Third, there is a considerable time-to-market pressure in the fast-changing world of computer engineering. (Did you know that Motorola lost to Intel when IBM designed the first PC because the Motorola processor was 6 months late? A 6-month slip in schedule forever changed the microprocessor landscape!) You have to get the design working and into mass production quickly, without much time to make or fix mistakes.

So, armed with this book, students and professionals can embark on successful digital designs. 